\title{
PERCEPTUAL MOTOR APPROACH LEBIH BAIK DARIPADA SPECIFIC BALANCE TRAINING DALAM MENINGKATKAN KESEIMBANGAN DINAMIS PADA ANAK DENGAN AUTISM SPECTRUM DISORDER (ASD) DERAJAT 1 DI PUSAT LAYANAN AUTIS KOTA DENPASAR
}

\author{
I Made Adi Widiantara ${ }^{1}$, Susy Purnawati ${ }^{2}$, Muh. Irfan $^{3}$, Cokorda Bagus Jaya Lesmana ${ }^{4}$, \\ Desak Made Wihandani ${ }^{5}$, Ketut Tirtayasa ${ }^{6}$ \\ ${ }^{1}$ Program Studi Magister Fisiologi Keolahragaan Universitas Udayana, Denpasar \\ ${ }^{2,6}$ Departemen Ilmu Faal Fakultas Kedokteran Universitas Udayana, Denpasar \\ ${ }^{3}$ Program Studi Fisioterapi Universitas Aisyiyah, Yogyakarta \\ ${ }^{4}$ Departemen Ilmu Kedokteran Jiwa Universitas Udayana, Denpasar \\ ${ }^{5}$ Departemen Ilmu Biokimia Fakultas Kedokteran Universitas Udayana, Denpasar
}

E-Mail: imadeadiwidiantara@gmail.com

\begin{abstract}
ABSTRAK
Latar Belakang: Anak dengan ASD termasuk dalam gangguan kesehatan mental yang menunjukkan gangguan pada kontrol motorik dasar, gangguan pada kinerja otot dan ketrampilan motorik konsisten dengan dispraksia yang sering menimbulkan gangguan berupa keseimbangan dinamis. Tujuan: Untuk menganalisis intervensi fisioterapi berupa Perceptual Motor Approach dan Specific Balance Training dalam meningkatkan keseimbangan dinamis anak dengan ASD. Metode: Penelitian ini menggunakan rancangan eksperimental penelitian two group pre and post test design. Responden pada penelitian melibatkan 22 anak ASD di Pusat Layanan Autis (PLA) Kota Denpasar yang dibagi menjadi dua kelompok. Sebelas orang anak pada Kelompok I diberikan Perceptual Motor Approach, sebelas orang anak pada Kelompok II diberikan Specific Balance Training. Latihan diberikan tiga kali seminggu selama delapan minggu. Keseimbangan dinamis diukur dengan Four square step test. Waktu saat melakukan Four square step test diukur dengan stopwatch. Semakin lama waktu yang diperlukan maka keseimbangan dinamis semakin buruk. Hasil: Hasil analisis data keseimbangan dinamis menggunakan paired sample t-test pada Kelompok I menunjukkan perbedaan bermakna dengan nilai $\mathrm{p}=0,000$ pada rerata sebelum intervensi $15,6 \pm 3,09$ detik dan setelah intervensi 11,7 \pm 2,90 detik. Paired sample t-test pada Kelompok II menunjukkan perbedaan bermakna dengan nilai $\mathrm{p}=0,010$ pada rerata sebelum intervensi $15,1 \pm 2,83$ detik dan sesudah intervensi 14,6 \pm 2,88 detik. Uji beda antara Kelompok I dan Kelompok II setelah intervensi menggunakan Independent sample t-test mendapat nilai $\mathrm{p}=0,030(\mathrm{p}<0,05)$. Simpulan: Perceptual Motor Approach lebih baik daripada Specific Balance Training dalam meningkatkan keseimbangan dinamis pada anak dengan ASD derajat 1 di Pusat Layanan Autis Kota Denpasar.
\end{abstract}

Kata Kunci : Autism Spectrum Disorder, Perceptual Motor Approach, Specific Balance Training, Keseimbangan Dinamis. 


\section{PERCEPTUAL MOTOR APPROACH INCREASES DYNAMIC BALANCE BETTER THAN SPECIFIC BALANCE TRAINING IN FIRST DEGREES AUTISM SPECTRUM DISORDER (ASD) CHILDREN IN AUTISM CARE CENTRE AT DENPASAR}

\section{ABSTRACt}

Background: Children with ASD are included in mental health disorders that show disturbances in basic motor control, disruptions in muscle performance and motor skills consistent with dyspraxia which often leads to disorders of dynamic balance. Purpose: To analyze physiotherapy interventions in the form of Perceptual Motor Approach and Specific Balance Training in improving the dynamic balance of children with ASD. Methods: This study uses an experimental research design of two groups pre and post test design. Respondents in the study involved 22 ASD children in the Autism Service Center (PLA) of Denpasar City which were divided into two groups. Eleven children in Group I were given the Perceptual Motor Approach, eleven children in Group II were given Specific Balance Training. The exercise is given three times a week for eight weeks. Dynamic balance is measured by Four square step test. The time when doing the Four square step test is measured with a stopwatch. The longer the time needed, the worse the dynamic balance. Results: The results of dynamic balance data analysis using paired sample ttest in group I showed significant differences with the value of $p=0,000$ in the mean before intervention $15.6 \pm 3.09$ seconds and after the intervention $11.7 \pm 2.90$ seconds. Paired sample t-test in group II showed significant differences with $\mathrm{p}=0.010$ in the mean before intervention $15.1 \pm$ 2.83 seconds and after intervention $14.6 \pm 2.88$ seconds. Different test between group I and group II after the intervention using Independent sample t-test got a value of $\mathrm{p}=0.030(\mathrm{p}<0.05)$. Conclusion: Perceptual Motor Approach is better than Specific Balance Training in improving balance dynamics on children with first degree ASD in autism care centre at denpasar.

Keywords: Autism Spectrum Disorder, Perceptual Motor Approach, Specific Balance Training, Dynamic Balance.

\section{Pendahuluan}

Kesehatan mental adalah isu yang diangkat dalam hari fisioterapi dunia tahun 2018. Isu ini menjadi sangat penting dalam peran fungsi fisioterapi dalam menangani gangguan kesehatan mental. Studi epidemiologis menunjukkan bahwa depresi, kondisi yang berhubungan dengan stress, gangguan muskuloskeletal yang berlangsung lama dan kecemasan mempengaruhi jutaan individu di seluruh dunia sering memiliki konsekuensi negatif untuk kemampuan mereka untuk bekerja dan kualitas hidup ${ }^{1}$. Hal ini pun terjadi pada anak-anak yang mengalami gangguan Autism Spectrum Disorder (ASD). Dampak biopsikososial yang juga mempengaruhi kualitas anak berpengaruh luas seperti dampak komunikasi sosial, prilaku berulang, gangguan ketrampilan gerak, serta pengaruh aktivitas kehidupan sehari-hari. Dalam aspek ketrampilan gerak aspek kontrol gerak, keseimbangan, penguasaan gerak, dan pemahaman gerakan dasar. Pada anak dengan ASD yang termasuk dalam gangguan kesehatan mental juga menunjukkan gangguan pada kontrol motorik dasar, gangguan pada kinerja otot dan ketrampilan motorik konsisten dengan dyspraxia ${ }^{2}$ dalam jurnal specificity of dyspraxia in children with autism. Kondisi dispraksia pada anak dengan ASD sangat erat hubungannya dengan koordinasi gerak serta gangguan keseimbangan tubuh. Anak dengan ASD sering mengalami gangguan pada keseimbangan. Gangguan keseimbangan dinamis pada anak dengan ASD dapat dilihat dari sikap berdiri dan berjalan yang terlihat goyah. Hal tersebut karena anak dengan ASD memiliki koordinasi yang buruk dari anggota gerak bawah selama kegiatan yang membutuhkan keseimbangan ${ }^{3}$. Fungsi 
motorik kasar seperti kontrol postur dan koordinasi gerak pun melibatkan struktur kortikal dan subkortikal yang luas. Sehingga defisit motor adalah inti potensial yang melengkapi ASD sehingga adanya gangguan keseimbangan yang mempengaruhi kontrol keseimbangan ${ }^{4}$. Tindakan terapi saat ini pun merujuk kepada intervensi dini dan berkesinambungan untuk mengurangi disabilitas pada anak dikemudian hari ${ }^{5}$. Yaitu tindakan latihan seperti perceptual motor approach dan Specific Balance Training atau pelatihan pada umumnya. Perceptual motor mampu meningkatkan hubungan perseptual dan motorik anak karena fungsi taktil, pengelihatan, pendengaran, proprioseptif, keseimbangan akan ditingkatkan kesadarannya sehingga daya paham akan meningkat. Sedangkan pada Specific Balance Training peningkatan kontrol postural menjadi landasan dalam meningkatkan keseimbangan, latihan ini pun sering dikombinasikan dengan latihan membuka dan menutup mata agar fungsi vestibular system meningkat ${ }^{6}$. Kemampuan tubuh untuk mempertahankan keseimbangan dan kestabilan postur oleh aktivitas motorik tidak dapat dipisahkan dari faktor lingkungan dan sistem regulasi yang berperan dalam pembentukan keseimbangan. Tujuan tubuh mempertahankan keseimbangan adalah menyangga tubuh melawan gravitasi dan faktor eksternal lain, untuk mempertahankan pusat massa tubuh agar sejajar dan seimbang dengan bidang tumpu, serta menstabilisasi bagian tubuh ketika bagian tubuh lain bergerak $^{7}$.

Penelitian ini pun dapat menunjukkan kontribusi yang lebih tinggi dalam mencari keseimbangan? Keseimbangan statis dan dinamis dilakukan dengan mata terbuka karena dominasi visual lebih tinggi dari rasa propioseptif untuk keseimbangan statis dan dinamis ${ }^{8}$. Kondisi ini pun melibatkan kontribusi aferen dari sistem kinestetik ke kontrol keseimbangan statis secara terus-menerus. Proses informasi visual ini pun penting untuk kontrol keseimbangan berbasis umpan balik. Di sisi lain, postural kontrol yang kurang seimbang juga berhubungan dengan kecepatan respon gerak, feedforward dalam mengontrol keseimbangan, proses pengolahan informasi sensorik dan kognitif pun menjadi kompenen yang harus diperhatikan saat latihan keseimbangan.

\section{HASIL PENELITIAN}

\section{Karakteristik subjek penelitian}

Subjek adalah anak dengan ASD derajat satu yang telah didiagnosa secara bersama-sama oleh tim (Psikologi klinis, psikologi, orthopedagogi, fisioterapi, okupasi terapi, dan terapi wicara) berusia 7-14 tahun yang mengalami gangguan keseimbangan. Karakteristik subjek penelitian meliputi: umur, jenis kelamin, berat badan, ,tinggi badan, dan IMT. Deskripsi karakteristik subjek penelitian pada kedua kelompok disajikan pada Tabel 1.

Tabel 1

Karakteristik subjek penelitian

\begin{tabular}{|c|c|c|c|}
\hline \multirow{2}{*}{$\begin{array}{c}\text { Karakteristik } \\
\text { subjek }\end{array}$} & \multicolumn{3}{|c|}{ Kelompok 1} \\
\hline & Rerata $\pm S B$ & Min & Maks \\
\hline Umur (th) & $10,8 \pm 1,54$ & 8 & 13 \\
\hline Berat badan (kg) & $35,0 \pm 5,31$ & 26 & 43 \\
\hline Tinggi badan $(\mathrm{cm})$ & $141,7 \pm 8,90$ & 128 & 158 \\
\hline IMT $\left(\mathrm{kg} / \mathrm{m}^{2}\right)$ & $17,3 \pm 1,08$ & 15,9 & $1^{9}, 1$ \\
\hline \multirow{2}{*}{$\begin{array}{c}\text { Karakteristik } \\
\text { subjek }\end{array}$} & \multicolumn{3}{|c|}{ Kelompok 2} \\
\hline & Rerata \pm SB & Min & Mak \\
\hline Umur (th) & $9,9 \pm 2,43$ & 7 & 14 \\
\hline Berat badan $(\mathrm{kg})$ & $32,1 \pm 6,72$ & 23 & 43 \\
\hline Tinggi badan $(\mathrm{cm})$ & $137,7 \pm 12,64$ & 122 & 160 \\
\hline IMT $\left(\mathrm{kg} / \mathrm{m}^{2}\right)$ & $16,7 \pm 0,95$ & 15,3 & 18,6 \\
\hline
\end{tabular}

Keterangan

Min : Minimal 
Mak : Maksimal

IMT : Indeks Massa Tubuh

\section{Uji Normalitas dan Homogenitas}

Berdasarkan Tabel 2, uji normalitas dan homogenitas keseluruhan data memiliki nilai p >0,05 dan menunjukan seluruh data pada masing-masing kelompok berdistribusi normal dan data keseimbangan homogen.

Tabel 2

Hasil uji normalitas (Saphiro Wilk Test)dan homogenitas (Levene's Test)

\begin{tabular}{ccc}
\hline Uji & Uji \\
Normalitas & $\begin{array}{c}\text { Homoge } \\
\text { nitas }\end{array}$ \\
Kel1 & Kel 2 & Nilai p \\
nilai p & nilai p & \\
\hline
\end{tabular}

Keseimbangan

Dinamis

Sebelum

$0,339 \quad 0,075 \quad 0,777$

Intervensi

Setelah $\quad 0,571 \quad 0,353 \quad 0,982$

Intervensi

Keterangan

Kel 1 : Kelompok 1

Kel 2 : Kelompok 2

3. Uji Beda Pengukuran Keseimbangan Dinamis Sebelum Dan Setelah Perlakuan Pada Kedua Kelompok

Tabel 3

Hasil analisis statistik pada kelompok 1 dan kelompok 2 menggunakan independent sample t-test

\begin{tabular}{|c|c|c|c|}
\hline Variabel & $\begin{array}{c}\text { Kelompok } \\
1 \\
\text { rerata } \pm \\
\text { SB }\end{array}$ & $\begin{array}{c}\text { Kelompok } \\
2 \\
\text { rerata } \pm \\
\text { SB }\end{array}$ & $\mathrm{p}$ \\
\hline $\begin{array}{l}\text { Keseimbang } \\
\text { an dinamis }\end{array}$ & $15,6 \pm 3,09$ & $15,1 \pm 2,83$ & $\begin{array}{c}0,68 \\
1\end{array}$ \\
\hline
\end{tabular}

$$
\begin{aligned}
& \text { sebelum } \\
& \text { intervensi } \\
& \text { (detik) }
\end{aligned}
$$

\begin{tabular}{|c|c|c|}
\hline $\begin{array}{l}\text { an dinamis } \\
\text { setelah } \\
\text { intervensi } \\
\text { (detik) }\end{array}$ & $11,7 \pm 2,90$ & $14,6 \pm 2,88$ \\
\hline
\end{tabular}

Keseimbang

an dinamis

Tabel 4

Hasil analisis statistik pada kelompok 1 dan kelompok 2 menggunakan paired sample t-test

\begin{tabular}{cccc}
\hline Variabel & $\begin{array}{c}\text { Sebelum } \\
\text { intervensi } \\
\text { rerata } \pm \text { SB }\end{array}$ & $\begin{array}{c}\text { Setelah } \\
\text { intervensi } \\
\text { rerata } \pm \text { SB }\end{array}$ & p \\
\hline $\begin{array}{c}\text { Keseimban } \\
\text { gan dinamis } \\
\text { kelompok 1 } \\
\text { (detik) }\end{array}$ & $15,6 \pm 3,09$ & $11,7 \pm 2,90$ & 0,000 \\
& & &
\end{tabular}

Keseimban gan dinamis

kelompok $2 \quad 15,1 \pm 2,83 \quad 14,6 \pm 2,88 \quad 0,010$ (detik)

Data pada Tabel 4 menunjukkan bahwa terjadi penurunan waktu dalam menyelesaikan tes (tes diselesaikan dengan cepat) yang berarti terdapat peningkatan keseimbangan dinamis pada kelompok 1 yang dilihat dari rerata keseimbangan dinamis sebelum intervensi nilai reratanya adalah 15,6 $\pm 3,09$ (detik), dan terjadi peningkatan setelah 8 minggu diberikan Perceptual Motor Approach dengan nilai reratanya adalah $11,7 \pm 2,90$ (detik). Hasil uji analisis dengan menggunakan Paired sample t-test didapatkan nilai $\mathrm{p}=0,000 \quad(\mathrm{p}<0,05)$ yang berarti $\mathrm{Ha}$ diterima yaitu yaitu Perceptual Motor Approach dapat meningkatkan keseimbangan dinamis pada anak dengan Autism Spectrum Disorder (ASD) derajat 1.

Pada Tabel 4 juga menunjukkan bahwa terjadi peningkatan keseimbangan dinamis pada kelompok 2 yang dilihat dari rerata waktu untuk melakukan four square step test sebelum intervensi pada kelompok 2 nilai reratanya adalah $15,1 \pm 2,83$ detik, dan terjadi 
penurunan waktu setelah pelatihan dengan nilai reratanya adalah $14,6 \pm 2,88$ detik. Penurunan waktu untuk melakukan four square step test menunjukkan bahwa terjadi peningkatan keseimbangan dinamis. Hasil uji analisis dengan menggunakan Paired sample $t$-test didapatkan nilai $\mathrm{p}=0,010(\mathrm{p}<0,05)$ yang berarti Specific Balance Training dapat meningkatkan keseimbangan dinamis pada anak dengan Autism Spectrum Disorder (ASD) derajat 1.

Tabel 3 menunjukan hasil analisis dengan menggunakan independent sample t-test pada kelompok 1 sebesar 11,7 $\pm 2,90$ detik dan pada kelompok 2 sebesar 14,6 $\pm 2,88$ detik dengan nilai $p=0,030 \quad(p<0,05)$. Data tersebut memiliki arti ada perbedaan keseimbangan dinamis yang signifikan setelah perlakuan antara kelompok 1 dan kelompok 2, dimana ada peningkatan keseimbangan dinamis pada latihan Perceptual Motor Approach dari rerata keseimbangan dinamis sebesar $11,7 \pm 2,90$ sedangkan peningkatan pada latihan Specific Balance Training dari rerata keseimbangan dinamis sebesar 14,6 62,88 . Maka dapat disimpulkan bahwa Perceptual Motor Approach lebih baik dari Specific Balance Training dalam meningkatkan keseimbangan dinamis pada anak dengan Autism Spectrum Disorder (ASD) derajat 1 atau Ha diterima.

\section{PEMBAHASAN}

\section{Perceptual Motor Approach Dapat Meningkatkan Keseimbangan Dinamis Pada Anak Dengan Autism Spectrum Disorder (ASD) Derajat 1}

Latihan Perceptual Motor Approach yang dilihat dari rerata keseimbangan dinamis sebelum intervensi nilai reratanya adalah 15,6 $\pm 3,09$ detik, dan terjadi peningkatan setelah 8 minggu perlakuan dengan nilai reratanya adalah $11,7 \pm 2,90$ detik.

Pelatihan Perceptual Motor Approach yang diberikan menstimulasi banyak komponen yang mempengaruhi keseimbangan seperti mekanisme adaptasi, strategi sensori, internal representasi,kekuatan otot, postural kontrol, visual, dan vestibular.
Stimulasi propioseptif juga ditambahkan pada program pelatihan dengan memberikan pelatihan yang merangsang timbulnya propioseptif. Setiap gerakan yang terjadi dalam satu sirkuit latihan, tidak hanya meningkatkan satu komponen dalam keseimbangan, namun keseluruhan komponen yang bekerja seperti organ visual ${ }^{9}$. Seperti pada pelatihan memantulkan bola ke bawah dan bergiliran melewati holahop yang sudah tersusun (merupakan latihan pada unilateral activity station 5) yang dapat meningkatkan input visual.

Saat latihan melompat melewati tongkat yang dipasang di cone, serta melalui tiga holahop yang diletakan di bawah lantai dengan jarak $20 \mathrm{~cm}$ (yang merupakan gerakan bilateral activity station 1) diperlukan kemampuan mempertahankan posisi atau untuk memastikan sesuai transisi antara posisi, kontrol postural beradaptasi dengan aktivitas sistem muskuloskeletal.

Sistem propioseptif akan meningkat dengan kontraksi otot dan menstimulasi mekanoreseptor yang berada pada golgi tendon otot. Dengan sinyal yang dibawa menuju korteks serebri akan mengatur kerja otot agonis dan antagonis yang akan menyeimbangkan otot ${ }^{10}$. Gerakan melompat di trampolin serta melakukan lompat tali (yang merupakan gerakan bilateral activity station 2) adalah latihan yang dapat merangsang proprioseptif dengan intensitas gerakan yang berulang-ulang akan memberi dampak proprioseptif yang baik.

\section{Specific Balance Training Dapat Meningkatkan Keseimbangan Dinamis Pada Anak Dengan Autism Spectrum Disorder (ASD) Derajat 1}

Penurunan waktu dalam kel latihan Specific Balance Training menunjukkan bahwa terjadi peningkatan keseimbangan dinamis.. Dalam hal ini latihan single leg stance, balance path, dynamic balanced, double leg yang dilakukan dengan repitisi dan durasi sebagai acuan tubuh untuk menjaga kontrol postur tubuh secara seimbang ${ }^{11}$.

Latihan kontrol postur pada papan keseimbangan juga dapat meningkatkan 
propioseptif. Saat berjalan pada papan keseimbangan tubuh akan mengaktifkan propioseptif untuk merespon tubuh dalam menjaga keseimbangan. Propioseptif membantu sinergis komponen otot bekerja dengan baik. ${ }^{12}$ Pada penelitian pada 13 anak dengan autism dengan diberikan intervensi latihan keseimbangan dan stimulasi propioseptif.

Perceptual Motor Approach lebih baik dari Specific Balance Training dalam meningkatkan keseimbangan dinamis pada anak dengan Autism Spectrum Disorder (ASD) derajat 1.

Keseimbangan dinamis setelah pelatihan pada kel Perceptual Motor Approach sebesar 11,7 2,90 detik dan pada kel Specific Balance Training sebesar $14,6 \pm 2,88$ detik. Data tersebut memiliki arti ada perbedaan yang signifikan setelah perlakuan antara ke dua kel. Komponen latihan dan bentuk latihan berkelanjutan menjadi faktor lain mengapa pelatihan Perceptual Motor Approach lebih baik dalam meningkatkan kesimbangan dinamis. Seperti dibahas dalam penelitian "The effect of perceptual-motor activities training on gross motor skills of autistic children" di mana tugas persepsi dan motorik mengukur aspekaspek kunci "perilaku motorik" yang digunakan untuk pemprosesan visual atau gerakan visual yang terpadu ${ }^{13}$.

Ketika anak-anak dengan ASD belajar kemampuan motorik banyak faktor seperti kognitif, fisik, kebugaran fisik, keterampilan gerak, berbagai tingkat keterampilan, motivasi, dan tujuan mungkin menjadi keunggulan untuk fasilitasi dalam hambatan dalam pembelajaran. Seperti diketahui keterampilan motorik salah satu keterampilan dasar untuk sekolah dan akademik belajar.

Peran komponen lain seperti atensi dalam latihan juga dapat membantu meningkat kontrol gerak pada anak dengan ASD. Penelitian "The effect of perceptualmotor training on attention in the children with autism spectrum disorders" menunjukan peran persepsi dan perhatian mencakup kemampuan untuk merumuskan tujuan dan rencana tindakan dan untuk mengikuti ini sambil menghadapi rintangan ${ }^{14}$. Bentuk latihan seperti "track" yang berkelanjutan dapat meningkatkan atensi anak dan kemampuan anak akan berkembang dalam menghadapi rintangan.

Dalam konsep pemprosesan sensorik dan motorik itu melibatkan banyak komponen (multisensor) dalam autisme. Pemprosesan multisensor merupakan konstruksi yang berguna untuk membuat konsep, proses sensomotorik, dan pengalaman persepsi anak dengan autisme. Pada Specific Balance Training komponen sensorik tidak bekerja penuh, dan lebih menekankan fokus latihan untuk komponen yang bekerja di dalamnya musculoskeletal, internal representasion, adaptasi mekanisme, neuromuscular synergis, visual tracking. Latihan Perceptual-Motor Training akan melatih anak dalam mencapai postural security, bilateral body awareness, motor plan, body scheme, dan ability to screen input yang memerlukan fokus serta atensi yang tinggi. Sedangkan anak-anak dengan ASD memiliki kebutuhan sensorik, emosi, dan komunikasi yang unik sehingga diperlukan pengalaman sensomotorik yang berulang dan menantang ${ }^{15}$.

\section{SIMPULAN}

1. Perceptual Motor Approach dapat meningkatkan keseimbangan dinamis anak dengan ASD derajat 1

2. Specific Balance Training dapat meningkatkan keseimbangan dinamis pada anak dengan ASD derajat 1

3. Perceptual Motor Approach lebih baik dari pada latihan Specific Balance Training dalam meningkatkan keseimbangan dinamis pada anak dengan ASD derajat 1

\section{DAFTAR PUSTAKA}

1. WHO. 2016 Seth Mnookin, World Bank Group, and World Health Organization. Making Mental Health a Global Development Priority 
2. Lindsey K. M. \& Stewart H. M. 2012. Specificity of Dyspraxia in Children with Autism Published in final edited form as: Neuropsychology. March p. 165-171

3. Bhat, A.N., Landa, R.J., \& Galloway, J.C. 2011.Current Perspectives On Motor Functioning In Infants, Children, And Adults With Autism Spectrum Disorders. Journal Of Physical Therapy.

4. Jamie M., Toby M., Fred B. 2018. Relationships Between Gross Motor Skills and Social Function in Young Boys With Autism Spectrum Disorder. Pediatric Physical Therapy : The Official Publication Of The Section On Pediatrics Of The American Physical Therapy Association

5. Ozonoff S., Gregory S. Y., Stacy G., Laura G., Adriana M. H., Joel S., Suzanne M., Susan H., Sally J. R. 2008. Gross Motor Development, Movement Abnormalities, and Early Identification of Autism. Journal of Autisme And Developmental Disorder

6. Cheldavi H., Saeid S. B., Seyedeh N., Shetab B.A, Mehdi Z.A., 2013. The effects of balance training intervention on postural control of children with autism spectrum disorder: Role of sensory information : Research in Autism Spectrum Disorders

7. Winter, D. A., Patla, A. E., Ishac, M., \& Gage, W. H. 2003. Motor mechanisms of balance during quiet standing. Journal of Electromyography and Kinesiology

8. Assaiante, C., \& Amblard, B. 1995. An ontogenetic model for the sensorimotor organization of balance control in humans. Human Movement Science, 14, $13-43$.
9. Kolb, H. 2011. Simple Anatomy of the Retina, The Organization of the Retina and Visual System (serial online. Update 2011. Available from : URL : http://webvision.med.utah.edu/book/parti-foundations/simple-anatomy-of-theretina/. Accessed date 29 Maret 2018. Page 67

10. Watson, M. A \& Black, F. O. 2008. The Human Balance System-A complex Coordination of Central and Peripheral Systems. Vestibular Disorders Association.Page 140.

11. Strang, J. F., Kenworthy, L., Dominska, A., Sokoloff, J., Kenealy, L. E., \& Berl, M. Wallace. 2010 Increased gender variance in autism spectrum disorders and attention deficit hyperactivity disorder. Archives of Sexual Behavior vol. 8 page 3

12. Rudiyanto. 2014. "Pemberian Latihan Keseimbangan Dan Stimulasi Proprioseptif Meningkatkan Postural Control Pada Anak Dengan Autism" (skripsi). Jakarta : Universitas Esa Unggul.

13. Chen, K. C., Chu, C. L., Yang, Y. K., Yeh, T. L., Lee, I. H., Chen, P. S. 2005. The relationship among insight, cognitive function of patients with schizophrenia and their relatives' perception. Psychiatry Clinical Neuroscience.

14. Afshari J. 2012 The effect of perceptualmotor training on attention in the children with autism spectrum disorders Research in Autism Spectrum Disorder.

15. Hemant K. 2018 A Comparative Study on Relationship between Quality of Life of Children with Autism Spectrum Disorder and Normal. International Journal of Research in Engineering, IT and Social Sciences. vol. 7 page 4 